\title{
The Realpolitik of Values-Based Practice: An Introduction to Part VI, Reflections
}

\author{
Bill Fulford
}

In this final Part of the book, we present three chapters reflecting on aspects of the challenges experienced by their authors in implementing values-based approaches in their respective contexts. This is the realpolitik of values-based practice. The challenges as we will see are real and really difficult. They are likely to be in some respects greater still for implementing a culturally enriched form of values-based practice-for one thing, a culturally enriched form of values-based practice necessarily involves an extended range and complexity of operative values. Though in this connection, we should not lose sight of the fact that, as many chapters in earlier Parts of the book have shown, engaging with cultural values brings with it many resources as well as challenges.

As Table 43.1 indicates, the three chapters in this Part fall naturally under three shared values identified by a group of us in the course of one of the writing development workshops we ran in connection with the book. The workshops are described further in our concluding chapter 47, "Co-writing Values: What We Did and Why We Did It". The shared values we adopted were adapted from a framework of similar shared values developed by $\mathrm{NIMHE}^{1}$ to support its work of policy

\footnotetext{
${ }^{1}$ NIMHE, the National Institute for Mental Health, England, was a policy implementation body set up by the UK government around the turn of the century. The derivation of the NIMHE Values Framework including its origins in expertise by experience as well as expertise by training is described in chapter 47.
}

\section{Authors}

The editors with input from the contributors to Part VI

\author{
B. Fulford ( $\square)$ \\ St Catherine's College, University of Oxford, Oxford, UK \\ e-mail: kwmf@kwmfulford.com
}


Table 43.1 Annotated table of contents for Part VI, Reflections

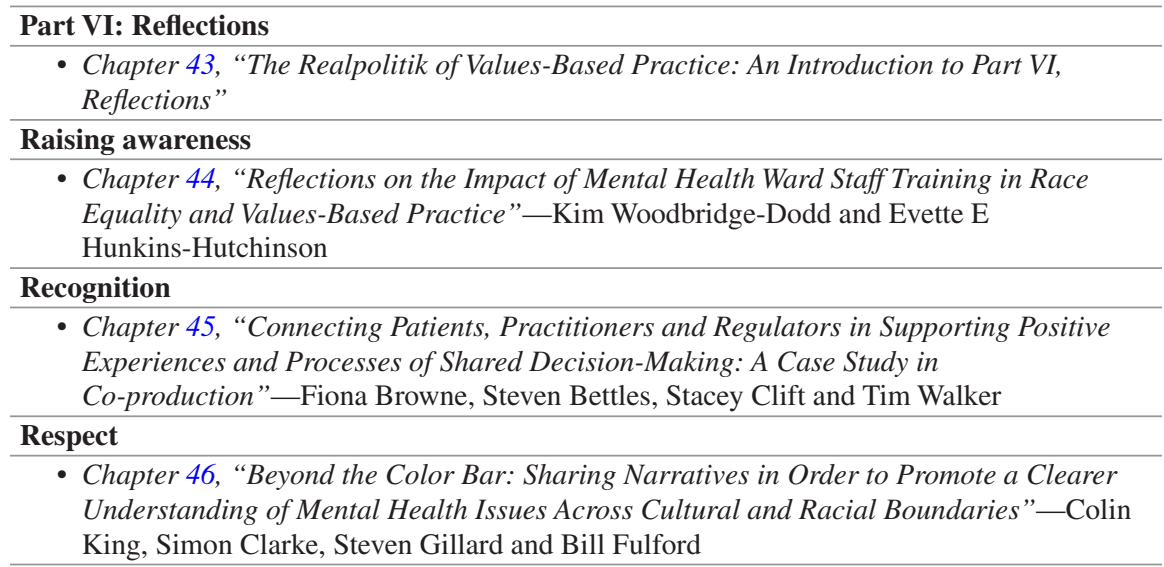

implementation. Dubbed the ' 3 Rs' of values-based practice, these are respectively, Raising Awareness, Recognition and Respect.

In the remainder of this chapter, we will first summarise the experiences of implementation described by contributors to this Part. As will be seen, the three chapters together provide powerful insights into the challenges of what it means to 'do' values-based practice for real. We will then contextualise these challenges within the framework of the ' 3 Rs' as this plays out across the book as a whole.

\subsection{The Three Projects}

First in line is a project illustrating the first of the ' 3 Rs', Raising Awareness of values.

\subsubsection{R for Raising Awareness}

As noted in chapter 1, "Surprised by Values: An Introduction to Values-Based Practice and the Use of Personal Narratives in This Book", raising awareness of values is the first and foundational skills area of values-based practice. Raising awareness turned out to be crucial in a project run by Kim Woodbridge-Dodd and Evette Hutchinson on which they reflect in chapter 44, "Reflections on the Impact of Mental Health Ward Staff Training in Race Equality and Values-Based Practice".

Kim and Evette's reflections on their project are presented in the form of a dialogue. In this dialogue, they look back on their experiences of first running and then evaluating the impact of a training project for front-line mental health ward staff 
that combined race equality with values-based practice. Kim (who is white) initiated, designed and organised the training and evaluation. She also delivered the values-based practice training. She is a nurse herself and was the operational manager of the staff completing the training. Evette (who is black) was external to the organisation and was invited to evaluate the programme. The project was funded and commissioned by an implementation arm of central government, the Care Services Improvement Partnership (CSIP). The ward was high achieving. The staff had recently gained a rare 'excellent' rating in a national assessment.

What stands out from Kim and Evette's vantage point of hindsight is the extent to which their early expectations of the training differed from what happened in practice, and how this was linked to their own cultural positioning in the project, respectively, as a white person (Kim) and a black person (Evette). In their dialogue, Kim and Evette candidly share their narratives of working through the difficulties and issues the training raised, such as the realisation that the white staff were finding the race equality training very challenging, and the black ward staff responses revealing their distress in relation to racism and dismissive attitudes or outright denial from their white colleagues. We come back below to the nature of these difficulties and the issues raised. As we will see, they provide a powerful illustration of the challenges of raising awareness of values in values-based practice.

\subsubsection{R for Recognition}

Chapter 45, "Connecting Patients, Practitioners and Regulators in Supporting Positive Experiences and Processes of Shared Decision-Making: A Case Study in Co-production" then follows with a project illustrating the second ' $R$ ' of valuesbased practice, Recognition. 'Recognition' in this context means recognising that (consistently with the Two-Feet principle of values-based practice, see chapter 1, "Surprised by Values: An Introduction to Values-Based Practice and the Use of Personal Narratives in This Book"), values come into all areas of health care including diagnostic assessment.

In chapte 45, Fiona Browne, Steven Bettles, Stacey Clift and Tim Walker describe their project. The authors of the chapter represent one of these constituencies-they are all health service regulators in the General Osteopathic Council (or GOsC, the regulator for osteopaths in the $\mathrm{UK}^{2}$ ). As a regulator, the $\mathrm{GOsC}$ might seem to some a perhaps surprising champion of values-based practice. 'Surprising' because regulation is widely regarded by practitioners as offering mainly a safety net against bad

\footnotetext{
${ }^{2}$ The GOsC is embedded in the statutory regulatory environment of health care in the UK. It is in turn overseen by the Professional Standards Authority, which reports on the performance of ten health and care professional regulators in the UK including the General Medical Council, the General Dental Council and others.
} 
practice. In this respect, regulation has sometimes had the unintended consequence of acting as a barrier to good practice. In mental health, notably, regulation is often blamed for producing a risk-averse culture that is inimical to recovery: this is reflected in Waldo Roeg's story (chapter 32, "Discovering Myself, a Journey of Rediscovery"), for example, where he notes that a more enlightened attitude to risk management was an important factor in his own recovery.

It is particularly encouraging therefore that it is as senior regulators that the authors of this chapter should have been active in driving their whole programme of supporting positive practice along values-based lines. As they describe, this involved exploring what matters to patients in an osteopathic consultation. But consistently with the inclusive approach to values of values-based practice, it also involved exploring what matters to osteopaths. It was in this regard a genuine co-production. And reflecting the Recognition ' $\mathrm{R}$ ' of values-based practice, what mattered to all stakeholders turned out to include not only how treatment was delivered but also how problems were assessed diagnostically. Again, we return below to the outcomes of the project and the challenges these present for implementation.

\subsubsection{R for Respect}

The third ' $R$ ' of values-based practice, Respect, directly reflects its premise. ' $R$ ' for Respect stands for the premise of values-based practice in 'mutual respect for differences of values' (see chapter 1, "Surprised by Values: An Introduction to ValuesBased Practice and the Use of Personal Narratives in This Book"). The importance of an underpinning premise of Respect particularly when cultural values are in play, is powerfully illustrated in this Part by Colin King, Simon Clarke, Steven Gillard and Bill Fulford's chapter 46, "Beyond the Color Bar: Sharing Narratives in Order to Promote a Clearer Understanding of Mental Health Issues Across Cultural and Racial Boundaries".

The narrative of this chapter is developed from Colin King' and his colleagues' very different perspectives on working together over a number of years on various projects aimed at improving inter-ethnic and cross-racial understanding in mental health. The stakes are high: in the UK (as in a number of other countries) young black men are many times more likely to be treated psychiatrically on an involuntary basis than their white counterparts; and there are indications that this may reflect cultural rather than medical factors-epidemiological studies for example show that the rates of disproportionate treatment follow administrative boundaries [1].

Small wonder then that as Kim Woodbridge-Dodd and Evette Hutchinson found in their combined race equality and values-based training programme (chapter 44, "Reflections on the Impact of Mental Health Ward Staff Training in Race Equality and Values-Based Practice"), the values issues raised are deeply conflicting. We had 
similar experiences of conflicting values in our writing workshops developing the book (described in our concluding chapter 47, "Co-writing Values: What We Did and Why We Did It"). And conflicting perspectives is exactly what Colin (who is black) and his colleagues (who are white) experienced. So conflicting indeed were their perspectives that without a shared commitment to the mutual respect underpinning values-based practice, their working relationship would surely have broken down long ago.

That their relationship has not broken down, that, as we describe further below, their project continues to make progress towards getting 'beyond the colour bar', shows the power of the premise of Respect underpinning values-based practice particularly where, as in this instance, it is cultural values that are in conflict.

\subsection{The 3 Rs}

That all three projects turned out to be in different ways difficult, indicates, if indication were needed, that values-based practice itself is difficult. Raising awareness of values is difficult; Recognition of the role of values in all areas including diagnosis is difficult: above all, Respect for differences of values is difficult.

\subsubsection{R for Raising Awareness}

The difficulty of the first $\mathrm{R}$ of values-based practice, Raising awareness of values, is well shown by Kim and Evette's shared learning from their programme combining race equality with values-based training. Their programme indeed captures much that is important about the role of cultural values in mental health. The ward culture enabled staff to engage with culturally compatible values such as the autonomy of service users (including their rights in relation to having choices), and in achieving improved mental health through narratives of recovery. It was these values that had led to the ward staff's coveted 'excellent' rating for their work with service users. But when it came to working across racial boundaries, discriminatory values soon came into play. With hindsight, this might have been anticipated. Ward culture after all is not free from wider societal cultural norms, beliefs and assumptions. In contrast to the wider society, however, the playing out of values in behaviours within the ward environment can be more open to scrutiny and observation, particularly, as in this instance, in training.

A further important point from Kim and Evette's reflections is about selfawareness. Kim and Evette's willingness to move beyond the theory of values-based practice and to expect it of their own behaviour, both at the time of the project and when reflecting back, enabled considerable learning from the experience. Perhaps as Kim and Evette surmise, earlier engagement in values-based practice and ways 
of understanding racism could have supported staff on the race equality training to achieve more equal and respectful ways of working together. Black and white staff members certainly believed that there would be benefit from continuing forums of the values-based kind in which the differences between them and their white colleagues could be explored in a safe space that supported mutual understanding and resolution.

We noted in chapter 1 (and again in chapter 15, "Vectors of Best Practice: An Introduction to Part III, Practice") our own failure of self-awareness in values-based practice as reflected in the unacknowledged values of individualism that had driven its development to date. This as we emphasised continued despite the philosopher Sridhar Venkatapuram's early observations to this effect [2].

There is a sense in which this whole book is about remedying that failure of self-awareness by focusing on the importance of cultural values at least in mental health (for of course they are important across the board). The importance of cultural values is clearly flagged in the exemplars given in Part I. Then again, many of the new theoretical resources highlighted in Part II are resources for raising awareness of cultural values: aesthetics, phenomenology and topicfocused resources such as feminist philosophy are all highly sensitive to cultural values; and African philosophy offers a range of resources for working with cultural values that have no direct counterparts in Western thought and practice.

Raised awareness of values was important too in the aspects of values-based practice covered in Part III. The different values represented by the 'extended multidisciplinary team' of values-based practice, these in turn providing a resource for the values-based concept of 'person-values-centred care', reflected the cultures of the different professions making up the multidisciplinary team. In Part IV, the examples included from the wider values tool kit were all 'tools' for working specifically with cultural values (trans-cultural ethics, anthropology, and reinforcing the message about the resources of African thought and practice, the use of indabas in policy making). Part V, training, was in a sense all about training for raised awareness of values. The first skills area is explicitly about 'raised awareness' but knowledge, reasoning, and communication skills, all contribute in values-based practice to the task of raising awareness. Notice again in this Part the importance of new resources for raising awareness available to a culturally enriched form of values-based practice: Michael Bennet's methodology (chapter 38, "Case Studies in the Culture of Professional Football Players and Mental Welfare and Wellbeing"), for example, combining expertise by experience with social science methods, Dharma therapy from Buddhism (chapter 35, "Dharma Therapy: A Buddhist Counselling Approach to Acknowledging and Enhancing Perspectives, Attitudes and Values") and the Disha project in India (chapter 41, "Disha: Building Bridges-Removing Barriers: Where Excluded and Privileged Young Adults Meet"). 


\subsubsection{R for Recognition}

The importance of the new resources available to a culturally enriched form of values-based practice is further evident in respect of its second ' $R$ ', RecognitionRecognition of the role of values alongside evidence in all areas of health care including diagnosis.

The importance of cultural values in diagnostic assessment in mental health is again evident in three chapters in Part I (chapters 3, "Antonella: 'A Stranger in the Family'-A Case Study of Eating Disorders Across Cultures", 4, "The Role of Culture, Values and Trauma in Shaping Abnormal Bodily Experience in Migrants" and 5, "Premorbid Personality and Expatriation as Possible Risk Factors for Brief Psychotic Disorder: A Case Report from Post-Soviet Bulgaria"). In each case, their exemplar narratives took us directly to the importance of these diagnostic cultural values. Diagnostic values were similarly evident in Part IV (chapters 25, "A CrossCultural Values-Based Approach to the Diagnosis and Treatment of Dissociative (Conversion) Disorders", 26, "Treatment of Social Anxiety Disorder or Neuroenhancement of Socially Accepted Modesty? The Case of Ms. Suzuki", 27, "Nontraditional Religion, Hyper-Religiosity, and Psychopathology: The Story of Ivan from Bulgaria" and 28, "Journey into Genes: Cultural Values and the (Near) Future of Genetic Counselling in Mental Health") covering the three principles defining the relationship between values and evidence in values-based practice in its role of linking science with people. The further links in the chain of connections linking science with people, to which we pointed in the introduction to that Part (chapter 24, "Linking Science with People: An Introduction to Part IV, Science"), running as it does from research through regulation to clinical guidelines, are all about cultural values. The selection of research topics is guided by cultural values. Research itself is driven by a strong set of cultural values (to which Steven Gillard points in his contribution to chapter 46, "Beyond the Color Bar: Sharing Narratives in Order to Promote a Clearer Understanding of Mental Health Issues Across Cultural and Racial Boundaries"). Regulation reflects the cultural values of the wider society (such as being risk-averse). The values of the wider society are also reflected in clinical guidelines to the extent that these are constructed by combining evidence with health economic values.

It is thus particularly apposite that chapter 45 , "Connecting Patients, Practitioners and Regulators in Supporting Positive Experiences and Processes of Shared Decision-Making: A Case Study in Co-production" should be by a health professional regulator, the General Osteopathic Council, regulation being itself a key link in the chain connecting science with people. As its authors describe, there were many difficulties in developing their project: the values of stakeholders were difficult to characterise, requiring a number of workshops using different methodologies. There will, as they anticipate, be further difficulties to come in evaluating the project. But they have led the way nonetheless in getting tangible results. Building 
on their foundational work on the values of the key stakeholders in osteopathic care, the General Osteopathic Council has produced a series of innovative resources to help osteopaths deliver care that is consistent with their own values while at the same time more effectively meeting the needs of their patients. Following their lead, similar developments are under way with other UK regulators (such as the General Dental Council); and the focus of the programme as a whole on positive practice is supported by the Professional Standards Authority (see the Guide to Further Information in chapter 45).

It is also apposite that chapter 45 , in representing the ' $R$ for Recognition' of values-based practice, should be about osteopathy. It might be thought that osteopathy being (primarily ${ }^{3}$ ) about bodily health, its processes of diagnostic assessment would be value free. To the contrary, as the story in chapter 45 illustrates, and as the resources produced by the programme make clear, the vectors of best practice in osteopathy no less than in mental health include diagnostic values. The example of osteopathy is the more striking as an instance of ' $\mathrm{R}$ for Recognition' because, as chapter 45 describes, with one exception, osteopaths start with enviably high patient satisfaction ratings. The exception is patients being less confident they have a sufficient say in how they are treated. In this respect, therefore, osteopathic patients share with service users in mental health a sense of loss of autonomy, suggestive of paternalistic practice. In mental health, moreover, as Waldo Roeg's story (chapter 32, "Discovering Myself, a Journey of Rediscovery") shows, restoring a sense of control is a first and often key step towards recovery. If therefor as chapter 45 shows, diagnostic values are important to restoring a sense of control in a discipline with such high overall patient ratings as osteopathy, they will hardly be any less important in mental health.

\subsubsection{R for Respect}

Like ' $\mathrm{R}$ for Recognition', the third ' $\mathrm{R}$ ' of values-based practice, ' $\mathrm{R}$ for Respect', is widely represented throughout this book. Values-based practice as we have several times indicated is premised on mutual respect for differences of values. As a premise therefor, we should not be surprised to find that ' $R$ for Respect' is pervasive. But the premise comes most decisively into its own in the outputs of values-based practice in balanced decision-making. Without mutual respect, the dissensus on which the distinctive balancing processes of values-based practice directly depend (see chapter 1, "Surprised by Values: An Introduction to Values-Based Practice and the Use of Personal Narratives in This Book") would simply not be possible.

\footnotetext{
${ }^{3}$ Osteopaths frequently see people whose bodily problems reflect psychological causes (such as stress-induced muscle tension) and most adopt a holistic biopsychosocial approach to assessment.
} 
The three chapters on balanced decision-making included in Part III (Practice) illustrate the dependence of dissensus on mutual respect for differences specifically of cultural values. This is well illustrated by Guilherme $(\mathrm{G})$ Messas and Maria Julia (MJFR) Soares (chapter 19, "Alcohol Use Disorder in a Culture that Normalizes the Consumption of Alcoholic Beverages: The Conflicts for Decision-Making") exploration of the role of cultural values in the context of treating alcohol use disorder in a culture that normalises alcohol consumption. In this context, cultural values are at the heart of the conflicts for decision-making they describe; and as their case narrative so vividly illustrates, resolving (or at any rate managing) these conflicts requires a capacity for dissensus; it requires, that is to say, a capacity for respecting what is important for the patient in question while at the same time not abandoning the clinician's own values of evidence-based interventions.

Other chapters in Part III provide important illustrations of the resources for Respect opened up by engaging with cultural values. Drozdstoy Stoyanov and Bill Fulford's chapter 20, "Living at the Edge of Compromise: Balkan Pluralism as a Resource for Balanced Decision-Making" and Werdie van Staden's chapter 21, "“Thinking Too Much": A Clash of Legitimate Values in Clinical Practice Calls for an Indaba Guided by African Values-Based Practice", both take us to the heart of the matter with the resources they respectively offer for managing pluralism. The essential pluralism of values-based practice as we noted in chapter 1, leaves it vulnerable to what the political philosopher Isaiah Berlin identified as the "challenge of pluralism'. This challenge arises from what Berlin took to be the fact that people generally default to monism: they want definite answers not balanced judgements. Berlin's challenge of pluralism, furthermore, is no merely theoretical challenge. To the contrary, it crops up in many areas of practice. It was evident in the UK for example in the difficulties experienced in implementing values-based practice in relation to involuntary psychiatric treatment [3] and to diagnostic assessment [4]. The example of Balkan pluralism (chapter 20, "Living at the Edge of Compromise: Balkan Pluralism as a Resource for Balanced Decision-Making") thus gives hope that the default to monism is, as Stoyanov and Fulford indicate, a learned not innate feature of human behaviour and hence one that in principle can be unlearned. Werdie van Staden's chapter (chapter 21, “"Thinking Too Much”: A Clash of Legitimate Values in Clinical Practice Calls for an Indaba Guided by African Values-Based Practice") complements this conclusion by illustrating the use of the African indaba as a powerful process through which the required learning demonstrably takes place.

All of which, coming back to chapter 46, "Beyond the Color Bar: Sharing Narratives in Order to Promote a Clearer Understanding of Mental Health Issues Across Cultural and Racial Boundaries", speaks to the importance of the experience of Colin King and his colleagues of the power of mutual respect in supporting dissensus. As noted above (and as described more fully in chapter 46) without mutual respect their project would have been pulled apart by the highly conflicting perspectives that as a racially mixed group they brought to it. As it is, however, they are 
making progress towards their aim of getting 'beyond the colour bar' and establishing co-production between people of different colours (black and white) in mental health.

The progress of the group, as their chapter describes, is partly by way of deeper theory, partly by way of practical outputs. As to theory, Colin King, drawing on the novel sociological and literary work on race of the turn-of-thecentury Black American writer, WEB Du Bois [5], and others, has introduced the concept of pre-production as a necessary prerequisite for genuine co-production. As to practice, Colin King (who is black) and Simon Clarke (who is white), working through their roles as joint leads of the Network for Whiteness and Race Equality in the Collaborating Centre for Values-based Practice in Oxford, have run a number of innovative sessions raising awareness of the cultural values in play in mental health. A further indication of the innovative nature of this programme is that working in collaboration with Michael Bennet (chapter 38, "Case Studies in the Culture of Professional Football Players and Mental Welfare and Wellbeing"), its outputs build in part on coaching models used in professional football.

\subsection{Conclusions}

That values-based practice is difficult is the message of the three chapters in this Part. Reflecting on their experiences of implementing values-based practice in their respective programmes, the experiences of the authors of the three chapters illustrate the difficulties presented by values-based practice, in raising awareness of values, in recognising the role of values in all areas of health care including diagnosis, and in maintaining the mutual respect by which values-based practice is underpinned.

These themes, as we have seen, reflected across the book as a whole, indicate the extent both of the additional challenges raised by and of the additional resources available from a values-based practice that is enriched by engaging with cultural values. All of which is good news for mental health. As a number of chapters in the book indicate, recovery in mental health depends critically on the three Rs of Raising awareness, Recognition and Respect.

\section{References}

1. Weich S, McBride O, Twigg L, Keown P, Cyhlarova E, Crepaz-Keay D, Parsons H, Scott J, Bhui K. Variation in compulsory psychiatric inpatient admission in England: a cross-sectional, multilevel analysis. Health Serv Deliv Res. 2014;2(49):90.

2. Venkatapuram S. Values-based practice and global health. Chapter 11. In: Loughlin M, editor. Debates in values-based practice: arguments for and against. Cambridge: Cambridge University Press; 2014. 
3. Fulford KWM, Dewey S, King M. Values-based involuntary seclusion and treatment: value pluralism and the UK's Mental Health Act 2007. Ch 60. In: Sadler JZ, van Staden W, Fulford KWM, editors. The Oxford handbook of psychiatric ethics. Oxford: Oxford University Press; 2015.

4. Fulford KWM, Duhig L, Hankin J, Hicks J, Keeble J. Values-based assessment in mental health: the 3 keys to a shared approach between service users and service providers. Ch 73. In: Sadler JZ, van Staden W, Fulford KWM, editors. The Oxford handbook of psychiatric ethics. Oxford: Oxford University Press; 2015.

5. Du Bois WD. The souls of the black folk. Oxford: Oxford University Press; 1903.

Open Access This chapter is licensed under the terms of the Creative Commons Attribution 4.0 International License (http://creativecommons.org/licenses/by/4.0/), which permits use, sharing, adaptation, distribution and reproduction in any medium or format, as long as you give appropriate credit to the original author(s) and the source, provide a link to the Creative Commons license and indicate if changes were made.

The images or other third party material in this chapter are included in the chapter's Creative Commons license, unless indicated otherwise in a credit line to the material. If material is not included in the chapter's Creative Commons license and your intended use is not permitted by statutory regulation or exceeds the permitted use, you will need to obtain permission directly from the copyright holder. 